\title{
EXPOSIÇÕES ITINERANTES DE ANIMAIS SELVAGENS, EM SÃO PAULO, NO SÉCULO XIX
}

\author{
Heloisa Barbuy'
}

\section{RESUMO}

Este artigo tem como objetivo evidenciar a presença de exposições itinerantes de animais selvagens na São Paulo do século XIX. Por terem se realizado, localmente, como uma entre outras atrações de circo, têm passado despercebidas como tipo específico de exposição popular, que conjuga funções de divertimento e instrução. Constituem objeto de interesse para estudos sobre a cultura de exposições do século XIX.

\section{PALAVRAS-CHAVE}

cultura material - exposições - história natural - São Paulo (cidade) - século XIX.

\begin{abstract}
This article aims to highlight the presence of traveling exhibitions of wildlife in São Paulo of the nineteenth century. For having done locally as one among other circus attractions, they have been overlooked as a specific type of popular exhibition, which combines fun and education functions. Are object of interest for studies on the exhibition culture of the nineteenth century.
\end{abstract}

\section{KEYWORDS}

material culture - exhibitions - natural history - Sao Paulo (city) - nineteenth century.

I Professora e curadora do Museu Paulista da Universidade de São Paulo. Na mesma Universidade, é professora do Programa de Pós-Graduação em História Social-FFLCH, do Programa de Pós-Graduação Interunidades em Museologia e Pesquisadora Associada da Biblioteca Brasiliana "Guita e José Mindlin". 
Em nossas pesquisas sobre uma cultura de exposições que se dissemina no século XIX e tendo São Paulo como campo empírico de investigação, deparamo-nos com um tipo de ocorrência, que eram as exposições de animais exóticos e selvagens - as feras, como estes eram então usualmente designados -, que se realizavam na cidade, incorporadas aos atrativos de circos que passavam pela capital da província paulista. Em anúncios e notícias publicados no jornal Correio Paulistano(CP), localizamos duas companhias circenses que apresentaram esse tipo de exposição na cidade, uma em 1866 e em I867 e outra em 1876. ${ }^{2}$ Examinaremos registros jornalísticos que deixaram suas passagens pela cidade, procurando, a partir deles, responder a algumas questões: quem eram, o que apresentavam (variedade de animais e formas de apresentação), como se anunciavam (publicidade), a que público(s) se dirigiam e como se dava a recepção de suas exibições, isto é, como se pode entender os significados que adquiriam no ambiente local.

Formas mais simples de expor animais já existiam nas práticas locais, como no caso de uma onça pintada que apareceu nos arredores da cidade e foi atacada e vencida, após duas horas de luta, por quatro tropeiros. Em seguida, o animal foi exibido ao público (já sem vida, supõe-se): "Acha-se este feroz animal hoje à exposição do público debaixo das figueiras do Arouche”(CP, I862,n. I77I: 4). Tratava-se de uma forma de oferecer à observação animais que normalmente não se poderiam ver detidamente, por habitarem as matas e por deles não se poder aproximar sem risco. Estas exposições tinham, assim, um sentido de atender à curiosidade popular, leiga. Ao mesmo tempo, porém, podiam responder também a um anseio por conhecimento científico, já que o interesse pela história natural se mostrava presente em diferentes esferas da vida social, considerando-se, inicialmente, o público letrado. Uma dessas esferas era, por exemplo, a existência de coleções particulares na cidade (GROLA et alii, 20I5). $\mathrm{Na}$ cultura de exposições, necessariamente vinculada às coleções, animais vivos ou o espécimes zoológicos preparados para serem conservados e exibidos são o cerne das práticas aí envolvidas. No Museu Sertório, que, nos anos de 1880 , reunia a coleção particular mais notória da cidade e que viria a ser o núcleo inicial de acervo do Museu Paulista, os espécimes zoológicos taxidermizados já tinham presença pronunciada (CARVALHO, 20I5, 20I4). Assim também o Museu Paulista, aberto ao público em 1895, em sua fase inicial era um museu de história natural com clara ênfase na zoologia (LOPES, 1997; GROLA, 20I4).

$\mathrm{Na}$ busca dos elementos que possam sutilmente ter se conjugado na formação de uma cultura de exposições e de umaprática colecionista em São Paulo, no século XIX, encontramos aspectos que vão em direção a uma valorização da ciência pela idéia de instituições voltadas ao estudo da natureza, em especial da zoologia, que se disseminava pela imprensa. De forma esparsa mas constante, desde pelo menos 1858 , começa a haver notícias a respeitos de jardins zoológicos europeus. Mesmo tendo uma tônica anedótica (quando não trágica), estas notícias, por trás dos fatos que relatam, introduzem, na imaginação do leitor, uma realidade - os cenários nos quais esses fatos se desenrolam. Ao narrar episódios como o nascimento de um camelo no Zoológico de Manchester ( $C P$, I866, n.2409: 3), a fuga de um crocodilo, morto por um elefante, no de Marselha (CP, 2734: 2) ou uma revolta de macacos no de Antuérpia (CP, I866, n.2785: 2), levam subjacentemente o leitor a imaginar aquele tipo de lugar que podia ser

2 Outros circos passaram pela cidade e traziam espetáculos com animais, sendo comuns os números eqüestres. Entretanto, não consta que oferecessem ao público exposições de animais selvagens do tipo que estamos examinando. 
percorrido por caminhos pontuados por grandes jaulas ou recintos em que se encontrariam animais selvagens, em seus movimentos e ações cotidianos, ao alcance da observação do visitante. $O$ Jardim Zoológico assim evocado é uma forma de coleção que ganha, no século XIX, uma nova conformação para se abrir ao grande público como museu vivo.

No campo da história dos museus, segundo Alexander (I979: I I0-I I6), as antigas ménageries, ${ }^{3}$ coleções de animais exóticos vivos, reunidos, na Europa, por reis e nobres, passam a ser franqueadas ao público. Serviam tanto à observação estudiosa como apenas ao deleite. Desde a segunda metade do século XVIII registram-se alguns casos precursores desta prática (Viena, Madri, Paris) e aos poucos as coleções de animais vivos vão ocupando espaços maiores. Duas iniciativas, segundo Alexander, marcam mudanças que levam das antigas ménageries em direção àquele tipo de estrutura que ficou conhecido como jardim zoológico: a criação, em 1828, em Londres, pela Zoological Royal Society, de um zoológico para fins científicos, que só mais tarde iria se abrir ao público, e um zoológico aberto em Hamburgo, em 1907, que, ainda segundo Alexander, se torna o protótipo do jardim zoológico que conhecemos. Entre um e outro, na segunda metade do século XIX,houve a criação de muitos zoológicos na Europa e nos Estados Unidos. Próximo de nós, em Buenos Aires, um zoológico foi inaugurado em 1875 e no Brasil, o primeiro jardim zoológico, na capital do Rio de Janeiro, data de 1888. ${ }^{4}$ Em São Paulo, o Jardim da Aclimação, cuja formação se iniciou em 1892, ${ }^{5}$ comportava um zoológico mas durou somente cerca de três décadas. Em 1935, o cronista Jorge Americano, em uma de suas crônicas-memória comenta a falta de um zoológico em São Paulo e refere-se a uma iniciativa de um particular que tinha uma coleção de animais em Santo Amaro (AMERICANO, 1962: 7475). O Jardim Zoológico de São Paulo, hoje existente, só viria a ser inaugurado em 1958. ${ }^{6}$ Portanto, na capital paulista de meados do século XIX, a possibilidade de instalação de um jardim zoológico era algo ainda distante.

Naquele contexto, porém, um tipo de espetáculo que, aos olhos de hoje, parece totalmente dissociado do mundo dos jardins zoológicos e sua base científica, podia, na verdade, ser tomado como um seu substitutivo: o circo. Com suas exibições de feras podia de fato pretender não apenas a diversão sem compromisso que dele se esperaria mas também suprir a curiosidade e o interesse de inclinação científica que havia em poder observar de perto os animais selvagens. Ao promover espetáculos que exibiam feras, o circo podia exercer também esta função. Foi o caso do circo do americano James Pedro Adams, ${ }^{7}$ que chegou à cidade, em meados de 1866, como "museu zoológico ambulante" e "companhia equestre" (CP, I866, n.3039: I).

\footnotetext{
3 O termo em francês é incorporado a várias línguas.

4 Trata-se do Jardim Zoológico de Vila Isabel, criado por iniciativa do Barão de Drummond e fechado nos anos 1940, conforme informação disponível no site oficial do atual Zoológico do Rio, inaugurado em 1945 e mantido pela Fundação Jardim Zoológico da Cidade do Rio de Janeiro - RIOZOO. Numa relação de zoológicos e aquários ativos em todo o mundo, publicada em 200I, consta que o mais antigo zoológico brasileiro em atividade é o Jardim Zoológico Museu Paraense Emílio Goeldi, inaugurado em Belém em I895 (KISLING JR., 200I: 388).

5 Iniciativa de Carlos José de Arruda Botelho, médico e secretário da Agricultura, que criou o Jardim da Aclimação em gleba de sua propriedade.

6 Cf. site oficial da Fundação Parque Zoológico de São Paulo.

$7 \mathrm{Em}$ sua origem o nome seria James Peter Adams, lembrando que no Brasil do século XIX era habitual a tradução dos nomes para o português.
} 


\section{Muzeu zoologico -0 muza zoologico ambu- lante, pertencente ao st, James Pedro Adams, o a sua companhia equestre chegaram hontem a esta cidade. Provavelmenty om poucos dias comegardö os espectat culos;annunciados.}

Figura I - Notícia sobre a chegada, a São Paulo, da companhia de James Pedro Adams, publicada no jornal Correio Paulistano (I866, n.3039: I).

http://memoria.bn.br/DocReader/docreader.aspx?bib=090972 02\&pasta=ano\%20186\&pesq=correio

Diplomático, Adams logo ofereceu a renda ("benefício") de um de seus espetáculos para ajudar nas despesas da Guerra do Paraguai, conseguindo que - Vice-Presidente da Província, que naquele momento era Joaquim Floriano de Toledo, nomeasse uma comissão para organizar a arrecadação (CP, 1866 , n.3035: I).Apenas por este fato já se pode dimensionar a repercussão que esse empreendimento lograva ter na capital paulista. A compra de bilhetes para o espetáculo contou com lista subscrita por figuras proeminentes da cidade, que saiu publicada no jornal (CP, I866, n.3I0I: 3). Não se pode garantir que estas tenham comparecido ao espetáculo mas que o prestigiaram, sim. Com a verba doada por Adams, quantidades consideráveis de café, açúcar e cigarros foram compradas e remetidas pelo Governo aos feridos de guerra (CP, I866, n.3082: 2). No início de agosto, prestes a partir, a companhia anunciava: "Ultimo dia da exposição das feras / $O$ diretor James Pedro Adams tem a honra de participar ao respeitável público que hoje 12 do corrente apresenta pela última vez a sua exposição zoológica nesta cidade" (CP, I866, n.3068: 3).

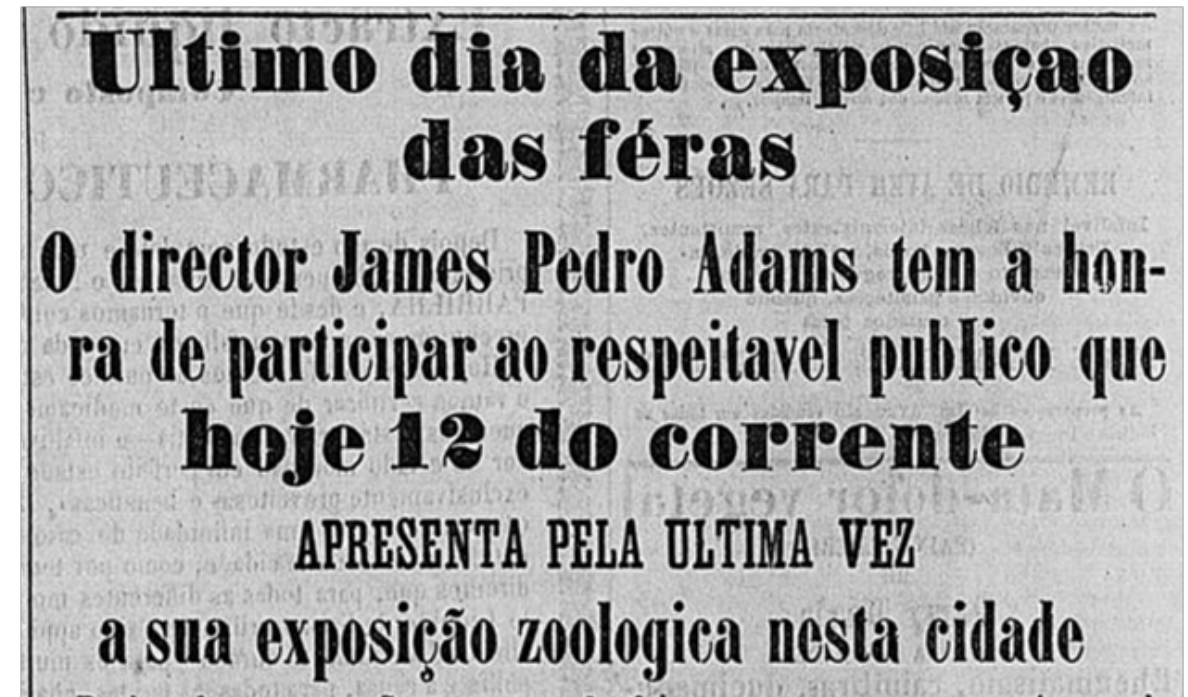

Retirando-se para Santos segunda feira espera a concurrencia geral. Principiará ás 8 horas da manhã até ás 5 e meia da tarde.

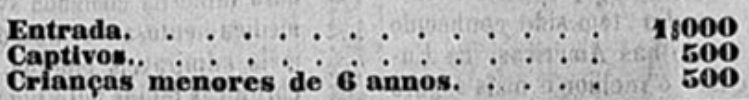

Figura 2 - Anúncio da companhia de James Pedro Adams publicado no jornal Correio Paulistano (1866, n.3068: 3).

http://memoria.bn.br/DocReader/docreader.aspx?bib=090972 02\&pasta $=a n o \% 20$ 186\&pesq=correio 
Ao comentar um período de calmaria em São Paulo, em razão da partida de espetáculos itinerantes que tinham animado a cidade, entre eles os de James Adams, um cronista, que usou o pseudônimo de Smarra, dava suas impressões sobre o dono da companhia, comparando-o a Noé ${ }^{8}$ e demonstrando assim que o mais marcante no circo de Adams seria, de fato, a variedade de animais que ele apresentava:

\begin{abstract}
O Adams, o velho americano que, para viver, equilibra cartuchos incendiados na ponta do nariz, o homem que traz às costas uma ambulância zoológica, o Noé do século XIX, pois que tem numa arca todos os animais conhecidos na superfície da terra, também deixou a cidade. Foi-se também ele, em busca de outros curiosos e amadores mais ferventes. / Que as águas do dilúvio (é meu desejo) Ihe sejam propícias, e, breve, mostrem-lhe algures as verdes e floridas encostas do Ararat, nas extensas solidões do indiferentismo público (CP, I866, n.3079: I).
\end{abstract}

Sobre o público que recebeu, observamos que os bilhetes custavam I $\$ 000$ e que havia meia entrada para escravos e para crianças menores de seis anos (CP, I866, n.3079: I). Podemos depreender, assim, que seu público era amplo, podendo ir desde os figurões da elite paulistana que subscreveram a lista em prol dos soldados da Guerra do Paraguai até escravos; desde adultos até crianças. Podemos supor que os resultados de público tenham sido satisfatórios pois este circo voltou à cidade em fevereiro do ano seguinte (CP, 1867, n.3228: 2). Desta vez houve apenas duas notas no Correio Paulistano sobre sua presença na cidade e por uma delas ficamos sabendo que os espetáculos circenses ocorriam à noite e que, durante o dia, a companhia conseguia arrecadação específica "expondo ao público algumas feras e outros animais que têm sido apreciados, mediante uma razoável contribuição pecuniária" (CP, I867, n.3215:2).

Quanto à itinerância da companhia de James Pedro Adams, pudemos acompanhar, pelo jornal Correio Paulistano, que ao sair de São Paulo, em agosto de 1866, foi se apresentar em Santos (CP, I866, n.3068: 3) e depois de sua segunda passagem por São Paulo, em fevereiro de 1867, dirigiu-se ao interior da província, mencionando, em anúncio, as cidades de Sorocaba, Tatuí, São Roque, Itapetininga e Pirapora (CP, I867, n.3275: 3).

Atenta ao contexto latino-americano, Irina PODGORNY (20I3) já apontou o quanto museus e coleções itinerantes constituem um universo ainda inexplorado de pesquisa e tem investigado alguns daqueles que passaram por Buenos Aires. Ao buscarmos melhor compreender o que seriam estas companhias itinerantes que apresentavam coleções de animais exóticos e selvagens, encontramos um referencial muito rico na obra de Helen COWIE (20I4), da Universidade de York, que realizou extensa pesquisa sobre exposições de animais na Inglaterra do século XIX. Em especial no capítulo 3 (COWIE, 20 I4:52-76), assim como em artigo de síntese sobre este tema (COWIE, 20I3), a autora aborda as várias coleçõesitinerantes de animais que circulavam pela Inglaterra, com caráter de empreendimentos comerciais, com base em abundante documentação, incluindo até mesmo um livro de registros do principal empreendimento inglês desse tipo, aquele de "George Wombwell, cujo nome logo se tornou sinônimo de coleções zoológicas itinerantes" (COWIE, 20I4: 57). A partir desta obra pudemos identificar, de fato, alguns elementos presentes nas práticas da compa-

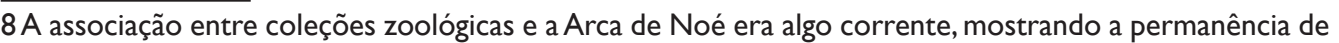
um referencial bíblico nas explicações sobre as origens do mundo, mesmo que pudesse haver uma conotação de humor. Essa frequente associação serviu, inclusive, para o título de uma obra publicada por ocasião do sesquicentenário da Zoological Society of London, The Ark in the Park (BLUNT, I976). 
nhia Adams, como sua presença em Sorocaba, no interior da província de São Paulo, justamente por ocasião da feira que se realizava tradicionalmente naquela cidade. Diz o anúncio:

\begin{abstract}
... O diretor desta companhia participa ao respeitável público sorocabano que pela ocasião da feira apresentar-lhe-á uma grande diversidade de trabalhos (...). / Além disso porá também à apreciação pública um grande quadro zoológico das mais raras e indomáveis feras da Europa, Ásia, África e América, e bem assim a maior serpente que se pode imaginar, pesando 10 a II arrobas - Sucuri. O preço para qualquer divertimento será - $\$ \$ 000 \ldots$... (CP 1867, n.3275: 3).
\end{abstract}

Esclarece Cowie, quanto a isso, que embora mais assíduas nas cidades maiores, as coleções zoológicas itinerantes usualmente incluíam, em seus roteiros, as cidades nas quais se realizavam as principais feiras anuais tradicionais do interior da Inglaterra (COWIE, 20I4:57-58), tal como eram tradicionais, aqui, as feiras de Sorocaba, tendo servido, assim, àquele tipo de estratégia comercial já estabelecido.As empresas inglesas criavam preços mais baixos para trabalhadores e crianças (COWIE, 20I4: 60), assim como, vimos acima, também se fazia nas apresentações de Adams em São Paulo, com meia-entrada para escravos e crianças.

O sentido geral dessas exposições itinerantes, casando a função de divertir com aquela de instruir - binômio característico do século XIX (BARBUY, 1999: passim) -, também foi constatado por Helen Cowie e, de fato, torna-se evidente pela simples observação dos anúncios. Fica explícito em publicidade da Companhia Chiarini, que se apresentou na cidade em maio de 1876, com circo instalado no Largo de São Bento. ' Entre as diferentes atrações que anunciava, sublinhamos algumas indicações: "Grande Circo Chiarini / Coleção zoológica" (CP, 1876, n.5858:4);" "uma coleção de feras muito rara e nunca vista neste país, dignas do mais minucioso estudo zoológico, harmonizando assim o recreativo com o instrutivo" (CP, 1876, n.5866: 3); "haverá espetáculo equestre, acrobático e agregação zoológica às 8 horas da noite" (CP, I876, n.5869: 4). O cronista anônimo do jornal ratificou:"além de grande pessoal artístico, traz a companhia uma coleção de feras, digna de ser vista e admirada". Havia grande afluência de público a esses espetáculos, segundo as narrativas do jornal.

O dono do circo, Giovanni Chiarini, pelo nome, presume-se, era italiano mas em sua companhia viam-se nomes de nacionalidades diversas. Tinha um administrador, Lourenço Maia e um agente, F.E. Picard, que assinaram, alternadamente, alguns de seus anúncios. Para cada tipo de animal, havia um domador como Lengel e Silvestre.

Pelo que se encontra nos registros do jornal, diferentemente da companhia de James Adams, o circo Chiarini não praticava a simples exposição de animais para serem vistos nas jaulas. No circo Chiarini, as feras eram mencionadas como dignas de interesse em si mas, ao que tudo indica, somente eram apresentadas em números circenses, sempre conduzidos por domadores. Destacava-se, porém, a oportunidade instrutiva que o circo representava pelo contato com as feras:

\footnotetext{
O diretor tem a honra de anunciar a todas as excelentíssimas famílias que não têm assistido as exibições dos raros animais ferozes e domesticados que possui (...), que aproveitem estas duas últimas funções, dando assim a conhecer às crianças estes animais não comuns neste país, dando-lhes o primeiro passo no conhecimento
}

9 O Largo de São Bento era o local destinado aos circos nos anos de 1840 a I860, segundo Ernani Silva BRUNO, em História e tradições da cidade de São Paulo, citado por Ricardo MENDES (2015). 
da zoologia. / Os corpos municipais de Londres, Paris, New-York, Berlim, Hamburgo e outras grandes capitais conservam seus agentes nos países remotos para comprar animais raros, a fim de reforçar as coleções dos jardins zoológicos. / Nas exibições ambulantes é raro encontrar-se espetáculos no pé do presente, que se torna recomendável por seus elementos meritórios. (CP, I876, n.5885: 4)

Quanto à itinerância dessa companhia, os registros do jornal permitem recompô-la, ao menos parcialmente. Em abril de 1876, anunciava o início, em breve, dos espetáculos em São Paulo (CP, 1876, n.5858:4). Depois de informado que entraria pelo Porto de Santos (CP, I876, n.5859: 2), em $I^{\circ}$ de maio chegava à cidade $(C P, 5864: 2)$ e fazia várias apresentações. Em junho estaria em Campinas (CP, 1876, n.5896: 2), em outubro em Niterói (CP, 1876, n.6004: 2), em julho de 1877 em Montevidéu (CP, 1877, n.6199: 3) e em outubro daquele ano em Buenos Aires (CP, I877, n.6285: 2). Note-se que o fato de o jornal paulistano noticiar, seguidamente, a presença do Circo Chiarini em diferentes cidades, mostra que os seus leitores poderiam continuar interessados em ter notícias da companhia.Anos antes, em 1870, uma pequena nota isolada havia informado que a companhia Chiarini tinha seguido da Côrte do Rio de Janeiro para a região do rio da Prata (CP, I870, n.4I59:2), o que confirma uma prática já estabelecida de itinerância internacional na América do Sul.

Um outro indicador de aferição sobre a popularidade da Companhia Chiarini é o fato de que no mesmo ano de $1876 \mathrm{em}$ que esta havia se apresentado em São Paulo, pouco depois de sua partida, o jornal humorístico $O$ Polichinello, redigido por Luiz Gama e ilustrado por Nicolau Huascar de Vergara (CAMARGO, 1981: 10), publicou uma charge com menção a Chiarini (O POLICHINELLO, 1876, n.13:4-5)

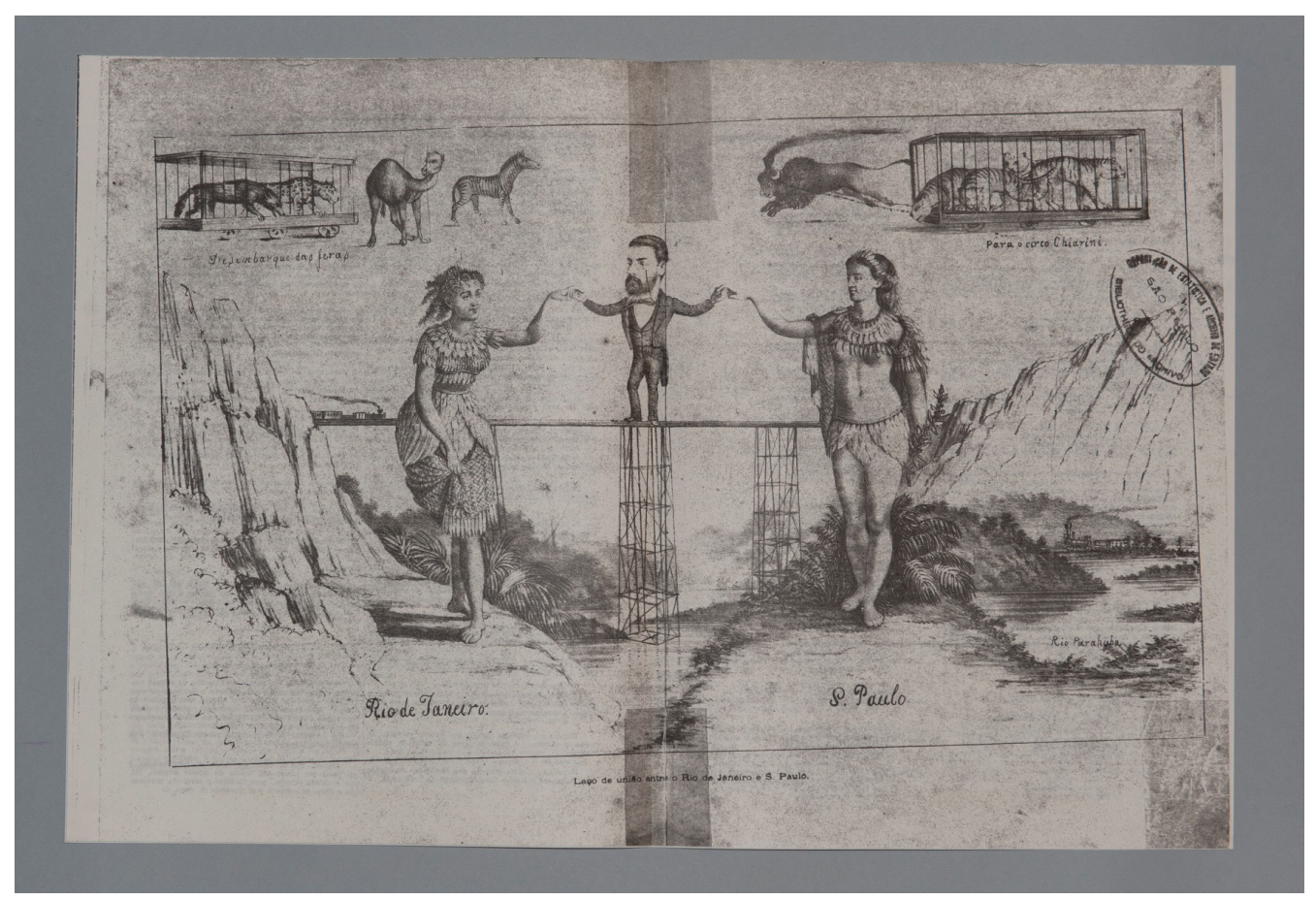

Figura 3 - Charge publicada no jornal humorístico O Polichinello (I876, n. I 3: 4-5). Na parte superior da gravura, referência à Companhia Chiarini. 
A charge fazia referência às obras ferroviárias que visavam à ligação da Província de São Paulo ao Rio de Janeiro.A figura masculina central, como pudemos deduzir, representa Clemente Falcão de Souza Filho - o Dr. Falcão Filho ${ }^{10}$ -, naquele momento superintendente da Companhia S. Paulo e Rio de Janeiro; as figuras femininas representam as duas províncias. De acordo com esta charge, por trem terão sido transportadas as feras do Chiarini, conforme pormenores na parte superior da gravura, sob a legenda "Desembarque das feras / Para o circo Chiarini". Podemos identificar parte dos animais como aqueles elencados nos anúncios da companhia. Da esquerda para a direita: um lobo, uma onça, um camelo (animais não mencionados nos anúncios que encontramos), uma zebra - "lindas zebras, as mais bonitas e melhor pintadas de sua raça, exibidas pelo artista inglês Frederico Silvestre" (CP, I876, n.5858: 4), que eram "zebras da Mauritânia” (CP, I876, n.5876: 4); um búfalo - "um grande búfalo norte-americano, o primeiro exibido no Brasil; de combinação com o qual se representarão ações intrépidas e seguidas pelos índios do Norte da América" (CP, I876, n.5858: 4); um grupo de tigres - "quatro belos e imponentes tigres reais de Bengala, os mais formosos de sua raça, domados pela inteligência do arrojado e intrépido domador de feras Her E. Lengel" - era destacada também "a grande jaula dos Tigres Reais" (CP, I876, n.5858: 4) ou

"Uma senhora na gaiola dos tigres! / Incalculável atrevimento! / Grande força de abnegação pessoal / A Sra. Emily Rowland, esta insigne artista equestre (...) penetrando no interior da jaula dos sanguinários tigres de Bengala, demonstrando o poder da inteligência humana sobre a força bruta, e imortalizando o seu nome nos anais desta cidade, com um acontecimento memorável" (CP, I876, n.5858: 4).

A única ilustração presente nos anúncios da companhia representam o búfalo, que se vê, na gravura, montado por um índio (CP, I876, n.5866: 3)

Fatos ocorridos depois com esse búfalo, em outras cidades, também foram acompanhados pelo jornal: em Niterói, esse animal (também chamado de bizonte) havia causado grande confusão, em consequência da qual um homem tinha fraturado uma perna (CP, I876, n.6004:2); em Buenos Aires, nova confusão: o búfalo ter-se-ia enfurecido e escapado, infundindo grande medo e tendo sido caçado durante sete horas. $O$ caso foi relatado com detalhes (CP, I877, n.6285: 2). Tudo isso pode ser visto como reverberações da passagem, em São Paulo, do circo e seus animais, que, presume-se, continuariam assim presentes no imaginário coletivo.

\footnotetext{
10 Esta dedução baseou-se, primeiramente, nas informações sobre esta companhia que constam dos relatórios do Presidente da Província, Sebastião José Pereira, de fevereiro e em fevereiro de 1877 RELATORIO apresentado á Assembléa Legislativa Provincial de S. Paulo pelo presidente da provincia, exm. sr. dr. Sebastião José Pereira, em 2 de fevereiro de 1876. S. Paulo,Typ. do "Diario," I876. p.26-28. e RELATORIO apresentado á Assembléa Legislativa Provincial de S. Paulo pelo presidente da provincia, o exm. sr. dr. Sebastião José Pereira em fevereiro de 1877. S. Paulo, Typ. do "Diario," 1877. p.72-73). Nesses relatórios são informados o trajeto, a realização dos diferentes trechos e a infraestrutura da ferrovia, e consta como superintendente da Companhia S. Paulo e Rio de Janeiro, responsável pelo empreendimento, o Dr. Falcão Filho. Em 2 de julho de 1876, a seção de Jacareí tinha sido inaugurada, sendo este o provável motivo de uma charge aparecer n'O Polichinello no dia 7 de julho daquele ano. O nome do Dr. Falcão Filho aparece também nos constantes avisos da companhia ferroviária publicados no Correio Paulistano.A hipótese de que a figura masculina central na gravura represente - Dr. Falcão Filho é confirmada por sua semelhança com o retrato a óleo dele existente no acervo da Faculdade de Direito, onde foi professor, obra do pintor Almeida Junior, datada de 1888. Apenas na charge, feita mais de 10 anos antes da pintura, o rosto está um pouco mais fino e em vez dos óculos, um monóculo. Os traços, porém, são os mesmos, o implante do cabelo, o nariz, os lábios e já o uso de barba e bigodes.
} 

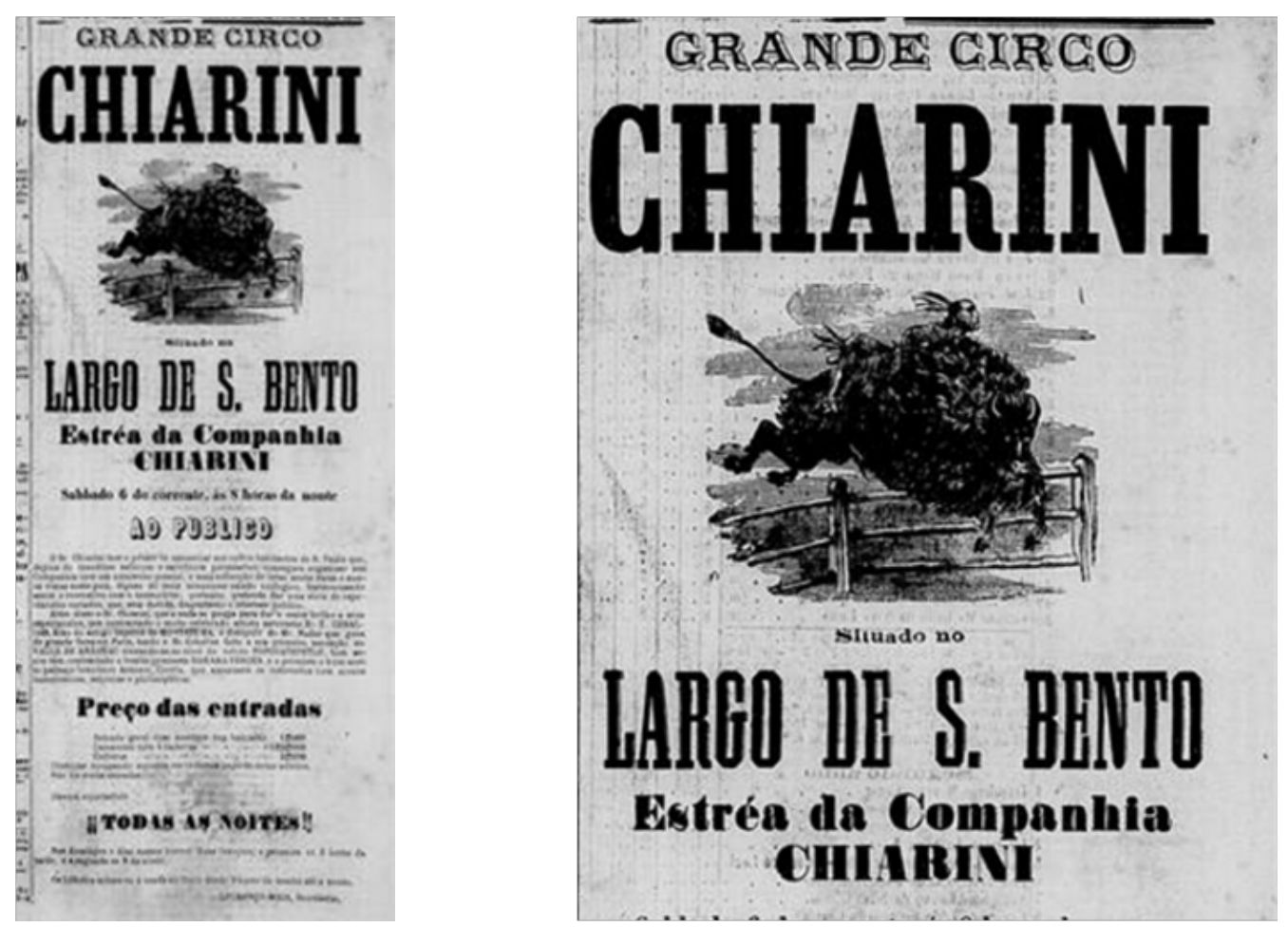

Figura 4 - Anúncio da Companhia Chiarini publicado no jornal Correio Paulistano (I876, n.5866: 3). A ilustração retrata o búfalo norte-americano que participava das apresentações, montado por um índio.

\section{Bibliografia e fontes}

ALEXANDER, Edward P.“From Menageries to Zoos”. In:ALEXANDER, E.P. Museums in Motion: an Introduction to the History and Functions of Museums. Nashville/TN:The American Association for State and Local History, 1979.

AMERICANO, Jorge. "Sobre um Jardim Zoológico (conversação em 1935)". In: AMERICANO, Jorge. São Paulo nesse tempo, 19/5-1935. São Paulo: Melhoramentos, 1962.

BARBUY, Heloisa.A Exposião Universal de 1889 em Paris: visão e representação na sociedade industrial. São Paulo: Loyola/História Social USP, 1999.

BLUNT,Wilfrid. The Ark in the Park:The Zoo in the Nineteenth Century. London: Hamish Hamilton / The Tryon Gallery, 1976.

BRUNO, Ernani Silva. História e tradições da cidade de São Paulo. 3.ed. São Paulo: Hucitec, 1984. 3v.

CAMARGO, Ana Maria de Almeida. "O Polichinello" (Introdução). In: O Polichinello edição fac-similar. São Paulo: Imprensa Oficial/Arquivo do Estado, 198I. (l.ed. 1876).

CARVALHO, Paula Carolina deAndrade.De uma "cientificidade difusa": o coronel e as práticas colecionistas do Museu Sertório na São Paulo em fins do século XIX. Anais do Museu Paulista: história e cultura material. São Paulo, v.23, n.2, p. I89-210, jul.-dez. 2015. Disponivel em http://www.scielo.br/scielo.php?script=sci issuetoc\&pid=0101$-47 \mid 420150002 \& \operatorname{lng}=p t \& n r m=i s o$

.O Museu Sertório: uma coleção particular em São Paulo no final do século XIX (primeiro acervo do Museu Paulista). Anais do 
Museu Paulista: história e cultura material. São Paulo, Museu Paulista-USP, v.22, n.2, p. I05-I I 5, jul./dez.20 I4. Disponível em http://www.scielo.br/scielo.php?pid=S0101$-47|420| 4000200005 \&$ script $=$ sci_arttext

CORREIO PAULISTANO (abrev. CP), jornal. Disponível em http://memoria.bn.br/ hdb/periodico.aspx Textos citados, cronologicamente:

ONÇA. Correio Paulistano, n. I77I, p.4, I abr. 1862.

UM CAMELLO EUROPEU. Correio Paulistano, n.2409, p.3, 3 I maio 1864.

PROEZA DE ELEFANTE. Correio Paulistano, n.2734, p.2, jul. 1865.

FURIA MACACAL. Correio Paulistano, n.2785, p.2, 7 set. 1865.

BENEFICIO PARA AS DESPEZAS DA GUERRA. Correio Paulistano, n.3035, p. I, 5 jul. I 866.

MUZEU ZOOLOGICO. Correio Paulistano, n.3039, p. I, 10 jul. 1866.

ULTIMO DIA... Correio Paulistano, n.3068, p.3., 12 ago. 1866.

SMARRA. Em falta de melhor. Correio Paulistano, n.3079, p. I, 26 ago. 1866.

DONATIVOS PARA OS FERIDOS. Correio Paulistano, n.3082, p.2, 30 ago. 1866.

RelaÇÃo dAS PESSOAS QUe ReCeberam e PAGARAM BilHeTES... Correio Paulistano, n.3I0I, p.3, 25 set. 1866.

ACHA-SE NESTA CIDADE... Correio Paulistano, n.3215, p.2, 13 fev. 1867.

ACHA-SE NESTA CIDADE... Correio Paulistano, n.3228, p.2, 28 fev. 1867.

CIRCO EQUESTRE E GYMNASTICO... Correio Paulistano, n.3275, p.3, 30 abr. 1867.

COMPANHIA CHIARINI. Correio Paulistano, n.4159, p.2, 19 maio 1870.

GRANDE CIRCO CHIARINI / COLLECÇÃO ZOOLOGICA. Correio Paulistano, n.5858, p.4, 26 abr. 1876.

COMPANHIA CHIARINI. Correio Paulistano, n.5859, p.2, 27 abr. 1876.

COMPANHIA CHIARINI. Correio Paulistano, n.5864, p.2, 3 maio 1876.

GRANDE CIRCO CHIARINI SITUADO NO LARGO DE S. BENTO. Correio Paulistano, n.5866, p.3, 5 maio 1876.

GRANDE CIRCO CHIARINI SITUADO NO LARGO DE S. BENTO. Correio Paulistano, n.5869, n.4, 9 maio 1876.

GRANDE CIRCO CHIARINI SITUADO NO LARGO DE S. BENTO. Correio Paulistano, n.5876, p.4, 18 maio 1876.

GRANDE CIRCO CHIARINI. Correio Paulistano, n.5885, p.4, 30 maio 1876.

GRANDE CIRCO CHIARINI SITUADO NO LARGO DE S. BENTO. Correio Paulistano, n.5886, p.4, 3 I maio 1876 .

COMEÇARÁ A TRABALHAR... Correio Paulistano, n.5896, p.2, 1 I jun. 1876.

NOTICIA A “PATRIA"... Correio Paulistano, n.6004, p.2, 27 out. 1876.

EMILIA ROWLAND... Correio Paulistano, n.6199, p.3, 4 jul. 1877.

O BUFALO DO CHIARINI. Correio Paulistano, n.6285, p.2, 16 out. 1877.

COWIE, Helen. Exhibiting Animals in Nineteenth-Century Britain: Empathy, Education, Entertainment. London: Palgrave Macmillan, 2014. 
COWIE, Helen. Elephants, education and entertainment: Travelling menageries in nineteenth-century Britain. Journal of the History of Collections, v. 25, n. I, p. I03III, 2013.

GROLA, Diego Amorim; CARVALHO, Paula Carolina de Andrade; BARBUY, Heloisa. Nurturing Collecting and the Trade on Objects:The Formation of the Museu Paulista, I850s- I 9I Os. Museum History Journal, v.9 n. I, p.93-I 07, January, 2016.

GROLA, Diego Amorim. Coleções de história natural no Museu Paulista, I 894- 19 I 6. São Paulo, 20I4. Dissertação de Mestrado - Faculdade de Filosofia, Letras e Ciências Humanas da Universidade de São Paulo. 190p. Disponível em http://www. teses.usp.br/teses/disponiveis/8/8138/tde-22102014-185744/pt-br.php

KISLING JR, Vernon N. (ed.) Zoo and Aquarium History: ancient animal collections to zoological gardens. New York: CCR Press, $200 \mathrm{I}$.

LOPES, Maria Margaret. O Brasil descobre a pesquisa científica: os museus e as ciências naturais no século XIX. I.ed. São Paulo: Hucitec, 1997.

MENDES, Ricardo. Circo em São Paulo: a contribuição do AHSP para sua historia.Informativo Arquivo Histórico de São Paulo. São Paulo:Arquivo Histórico Municipal "Washington Luís", v. I I, n.38, ago. 20 I5. Disponível em http://www.arquiamigos. org.br/info/info38/i-ensaio2.htm

O POLICHINELLO (jornal), n.I3, p.4-5, jul. 1876.

PEREIRA, Sebastião José. Relatorio apresentado á Assembléa Legislativa Provincial de S. Paulo pelo presidente da provincia, exm. sr. dr. Sebastião José Pereira, em 2 de fevereiro de 1876. São Paulo:Typ. do “Diario”, 1876.

Relatorio apresentado á Assembléa Legislativa Provincial de S. Paulo pelo presidente da provincia, o exm. sr. dr. Sebastião José Pereira em fevereiro de 1877. São Paulo:Typ. do “Diario”, 1877.

PODGORNY, Irina.Travelling Museums and Itinerant Collections in Nineteenth-Century Latin

America. Museum History Journal, v. 6, n. 2, p. I27-I46, July 20 I3.

\section{Sites citados:}

Fundação Jardim Zoológico da Cidade do Rio de Janeiro - RIOZOO: http://www. rio.ri.gov.br/web/riozoo/exibeconteudo?article-id=92715 .

Fundação Parque Zoológico de São Paulo: http://www.rio.rj.gov.br/web/riozoo/ exibeconteudo?article-id=927I5 